\title{
NERUDA ENTRE DOS SIGLOS
}

\author{
LUIS SAINZ DE MEDRANO
}

Catedrático de literatura hispanoamericana en la Universidad Complutense, es autor de Letras de la Nueva España (1992), La conquista literaria del Cono Sur (1992), Pablo Neruda. Cinco ensayos (1996), así como de una Historia de la literatura hispanomericana (1976, 1989), entre otros. Ha publicado numerosos artículos y es director honorario de Anales de literatura hispanoamericana. Ha dirigido congresos, entre ellos el del Instituto Internacional de Literatura Iberoamericana de 1984, institución de la que fue presidente entre 1983 y 1985. Desde 1976 imparte un curso de doctorado sobre la poesía de Pablo Neruda.

Permítasenos insistir, para comenzar, en algo bien sabido: como colofón de una etapa entusiasta, vitalista, la que va del Canto general (1950) al Tercer libro de las odas (1957)1, Neruda ofrece un libro inesperado, Estravagario (1958), en el que se plantea una reflexión escéptico-irónica en torno al mundo y a su propio quehacer poético. Es el tercer importante cambio de registro en su obra, si consideramos la unidad que hay en una primera etapa que va desde Crepusculario hasta que (segunda etapa) aparecen los ardorosos y comprometidos poemas de España en el corazón (1937), libro que hay que vincular ya al humanismo abierto hacia la otredad del Canto general.

Estravagario es un libro decisivo, pero después de él, Neruda no va a dejarse vencer, sin más, por un impulso de 'desengaño'. Desde Navegaciones y regresos (1959) hasta Las manos del día (1968) produce entusiastas poemas políticos (Canción de gesta, 1960), escudriñadores emocionados del pasado (Memorial de Isla Negra, 1964), risueñamente lúdicos (Arte de pájaros, 1966), defensores de la poesía que cuenta y canta ( $L$ a barcarola, 1967). Nada, excepto un pequeño libro que pasa bastante inadvertido (Aun, 1969), hace prever un nuevo momento de crisis.

Ésta, sin embargo, no ha dejado de seguir germinándose, y saldrá a la luz como resultado de un segundo momento de fatiga espiritual. Ahora el resultado es más dramático: el libro Fin de mundo (1969). El poeta, desde la altura de sus 65 años, se siente inclinado a revisar de nuevo su camino. Y esta vez lo hará ocupándose - desde la inevitable referencia a su recurrente yo- de acontecimientos heterogéneos concernientes a un siglo que, a treinta y un años todavía de su final (contando desde la fecha de publicación del libro), contempla en trance de liquidación pero obstinado en no concluir: "Qué siglo permanente./ Preguntamos:/ ¿Cuándo caerá? ¿Cuándo se irá de bruces/ al compacto, al vacío/ ¿a la revolución idolatrada?/ ¿o a la definitiva/ mentira patriarcal?» ("Prólogo").

Interesa reflexionar sobre la ironía que concierne a «la revolución idolatrada». Ya en Aún, escrito al parecer paralelamente a Fin de mundo, Neruda había anticipado esta misma posición al referirse a «el joven con su tierna indigestión de guerrillas» (XXVII). Parece que para entonces el poeta - como los grandes aparatos del partido- había perdido su confianza en las aventuras de ese tipo, tan abundantes como malhadadas en la América hispana, con excepción de la Revolución cubana. No creemos que se debiera a cuestiones de resentimiento, por el episodio que luego mencionaremos, sino a una convicción amarga, su desabrido comentario ante el trágico final del Che Guevara en Bolivia, en octubre de 1967, según cuenta Pierre Kalfon². Esto no impide que el poeta Neruda exalte al héroe -del que se supo era portador del emblemático Canto general en su última aventura - en las páginas de Fin de mundo ("Tristeza en la muerte de un héroe", III).

Al llegar aquí, cabe una consideración de interés: Neruda no ha titulado su libro Fin de siglo sino Fin de mundo. Esto evidentemente significa que el poeta no está solamente declarando cancelado y sentenciado el siglo $\mathrm{XX}$ sino algo más importante: el juicio y la condena se proyectan sobre las grandes expectativas generadas en vano por un mundo que ya definitivamente ha quedado petrificado,
1

Aun aceptando, en parte, con Jorge Edwards, cuyas palabras recogeremos después, que se percibe en este libro un cambio de tono -limitado en nuestra opinión. La causa residiría en que Neruda estaba ya en esa época afectado por acontecimientos políticos y personales.

2

P. Kalfon, en su libro Che. Ernesto Guevara, una leyenda de nuestro siglo (Barcelona, Plaza \& Janés, 1997, p. 600), reproduce este comentario del poeta a su antiguo camarada Sergio Insunza, quien se mostraba muy afectado ante el hecho: «文ero qué te pasa? ¡Si a los que tenemos que admirar y respetar es a los Recabarren [uno de los fundadores del partido comunista chileno, no a estos jóvenes ilusos que andan haciendo locuras».

Neruda entre dos siglos LUIS SAINZ DE MEDRANO 
inmovilizado en la perversidad. La opción entre «la revolución idolatrada» y la «definitiva/ mentira patriarcal» ya ha sido resuelta — se deduce- en favor de la segunda. Por otro lado, el poeta ha recibido, además del demoledor impacto de la desintegración del estalinismo en un pozo de horrores, y el de otros terribles episodios de lo que fue el promisorio "socialismo", una insoportable afrenta por parte de sus camaradas cubanos en la famosa carta al «compañero Pablo», dura recriminación por sus visitas a Nueva York (conferencia en el PEN Club Internacional) y a Lima (condecoración del presidente Belaúnde), en 1956.

No es un acto de convencional erudición enlazar este desaliento con el manido pero nunca suficientemente evaluado tema de la posmodernidad, con sus vanguardias inmovilizadas en formol, el arte que no se resigna a envejecer, los grandes relatos arrumbados - según el futuro análisis de Lyotard- (con qué melancolía contemplaría Neruda su Canto general arrumbado en el cementerio de los elefantes), la aldea global —donde se habían fundido ya, en el ámbito de la urbe imperial, la lluviosa Temuco, las nieves de antaño de París y las viejas ciudades de la gloria-, bajo la mirada implacable del Gran Hermano que ha dictaminado el fin de la historia.

Indecisión, incomunicación, pobreza, torturas, crueldad... En cierto modo, el citado poema inicial vuelve a justificar el viejo concepto que, a nuestro entender, explica el título de Residencia en la tierra, porque la tierra es una cárcel implacable de la que no se puede huir: «Cuando cayó la Bomba/ (...) pensamos irnos con el atadito,/ cambiar de astro y de raza/ (...)/ Queríamos irnos de aquí,/ lejos de aquí, más lejos» ("Prólogo"). Se abre en el poema la expectación hacia el tiempo ya inútil antes de aparecer, como ese «mañana/ que nacerá tan viejo» anunciado en su día por el Machado de Campos de Castilla.

En esta antesala, por mucho que el lamentable siglo se empeñe en no despedirse, el poeta, con algún síntoma ya de su mortal enfermedad, a partir de la experiencia de quien no se ha acostumbrado fácilmente a envejecer ( Me costó mucho envejecer,/ acaricié la primavera/ como a un mueble recién comprado/ de madera olorosa y lisa» "El mismo", I) y más aún a que envejezcan sus sentimientos y esperanzas, advierte con melancolía, frecuentemente irritada, cómo el tiempo ha ido desmantelándolas. En consecuencia, el gran verbalizador no puede dejar de organizar un inventario de afrentas y estragos emanados del siglo XX. Como ha escrito Jorge Edwards, en este libro se inicia un ciclo definitivo donde «la visión revolucionaria del término de la historia, del fin de la contradicción en la sociedad, del advenimiento del paraíso en la tierra [una posmodernidad de signo social, apostillamos], sería radicalmente reemplazada por la visión de la muerte propia y de la transformación del apocalipsis personal» ${ }^{3}$.

No pocos poemas, como es previsible, tienen neto carácter político. En primer lugar aparece la represión de la llamada «Primavera de Praga» en 1967 y el impacto causado en aquéllos que habían hecho lo posible por superar el trauma de la denuncia de los crímenes de Stalin realizada por Jruschov en el XIX Congreso del Partido comunista soviético (febrero 1956), teniendo en cuenta, además, que, en su caso, Neruda había recibido el premio que llevaba el nombre del dictador. Esforzarse en silenciar la íntima repulsa a la invasión de la capital checa en nombre de un ideal, de todos modos, inmarcesible, fue un costoso empeño: «Sufrí, sufrimos de no defender/ la flor que se nos amputaba/ para salvar el árbol rojo/ que necesita crecimiento (...)/ Fue fácil para el adversario/ echar vinagre por la grieta, / y no fue fácil definir/ y fue más difícil callar (...)/ y no fue fácil definir/ y fue más difícil callar.» Dramático poema éste en el que Neruda reconoce su voluntaria ceguera en aquel trance y solicita perdón por ello, mientras «se cierran las puertas del siglo / sobre los mismos insepultos» que volverán a llamarnos en vano, a la vez que la irrenunciable utopía social obliga a desviar la vista de ellos (“1967”, I).

Siglo que cubre con yeso «la vida evidente», «falso siglo victorioso» ("El tiempo en la vida", I), siglo que ha impuesto horrores sobre «la vida lineal,/ la limpieza de los rectángulos,/ la geometría sin recodos" ("Otra vez", I) y sobre los seres puros. Siglo de la Bomba. Siglo también, ciertamente, de la referida infamia estalinista, someramente apuntada inicialmente, de catástrofes naturales y de guerras calientes y frías ( «la edad fría de la guerra,/ la edad tranquila del odio» ("Sepan lo que sepan", II), tan absurdas como 
terribles, de mentiras compartidas con amigos y recibidas de enemigos, de fundamentalismos religiosos ante las pasiones humanas. Nuevas ruinas que prolongan las de España en el corazón y las dolorosas de Machu Picchu, de pies cercenados, carnes asesinadas. Siglo de idealistas luchadores - Ben Bella, Ben Barka, Lumumba-, del escondido infierno repleto de oportunistas, que el poeta contempla mientras se excusa por su ingenui$\mathrm{dad}$, su inoperancia, sus inevitables inducciones a la tristeza.

Siguiendo de nuevo a Jorge Edwards, con el matiz que antes hemos anotado, se percibe que «en los libros de la época estalinista, la noción del tiempo, precisamente, era lineal. El tiempo era una flecha dirigida hacia el futuro y que iba a dar en el blanco de la victoria y de la sociedad feliz...» Esto cambia en Tercer libro de las odas y en Estravagario, donde «encontramos que el tiempo se había convertido en círculo y en punto de interrogación» ${ }^{4}$. La centuria, periclitada de facto, pese a su terquedad, nada positivo añadirá a las amarguras de que ha sido portadora: "Treinta y dos años ${ }^{5}$ entrarán/ trayendo el siglo venidero,/ treinta y dos trompetas heroicas, / treinta y dos fuegos derrotados, / y el mundo seguirá tosiendo/ envuelto en su sueño y su crimen" ("El siglo muere", III). Siguen más reflexivas, dolorosas nostalgias: los Estados Unidos de Lincoln y de Whitman se hicieron luego depredadores en Viet-Nam.

Nada de lo expuesto hasta aquí acaba de ser sorprendente en último término. Sí lo es el juicio que a Neruda le merecen aspectos fundamentales de la cultura que ha impregnado este siglo. Grandes mitos del pasado lo presiden de modo abrumador: "Mozart, el suave enlevitado»; Dostoyevski («folletín», «tinieblas», «espinas»); Rimbaud, «el vago vagabundo", la interminable lluvia de Verlaine; el paraguas, a pleno sol, de Baudelaire; el ajeno («no nos pertenece») autor de Hojas de hierba, a pesar de la reciente y emotiva evocación ("El XIX", IV). Estamos, naturalmente, ante una provocación de quien con seguridad no sostendría tamañas agresiones contra el principio de autoridad fuera de un contexto poético; agresiones que alcanzan a los pesados huesos de Balzac, Hugo, Zola, Emilia Bronte y Mallarmé. Afortunadamente Neruda cuenta aquí con un triturador de sacralidades con quien se solidariza: el Jarry de Ubu Roi, aso- ciado, por su escatológica desmesura, al dadaísmo.

Claro que el mismo poeta no puede escapar a su autocontemplación. Surgen disquisiciones sobre su condición de poeta pragmático y escéptico, resignado con sus propias ataduras, contemplador de sus paisajes esenciales y de un fascinante e incomprensible bestiario. Claro que tras considerar su personal poética, inmune a los convencionalismos de la vanguardia e irónicamente resignado a su status de anticuado, seguirá revisando su entorno más convulsivo: el desastre ecológico, las ciudades vencidas por la técnica, el horror nuclear, la ineluctable memoria de la guerra española, Praga de nuevo. El siglo caduco-interminable es al parecer, desgraciadamente, cíclico.

Entrando decididamente en un aspecto muy penoso, se define inequívocamente la abominación de Stalin y su genocidio tardíamente descubierto, aunque también la ratificación de la fe en el ideario por él mancillado. A esto se une también la repulsa al omnipotente dictador chino Mao-Tse-Tung. Claro que no por ello se baja la guardia ante la agresión al Viet-Nam de los hombres del pentágono.

Pero la obsesión autobiográfica sigue imponiéndose, de tal forma que, durante un largo espacio (VII y VIII partes) el discurso nerudiano se convierte en una serie de consideraciones en torno a su emisor. Se trata, en efecto, de una corriente subliminar de datos que reconstruyen, por la vía de lo simbólico, su itinerario vital, incluyendo, por supuesto, sus esenciales visiones del mundo, con alguna excepcional aproximación a lo anecdótico.

Luego entran en este juego distintas especificaciones geográficas - Punta del Este, Río, Caracas, el sur chileno- que comportan eventuales aproximaciones a lo social, especialmente en el tema de las descolonizaciones. Sorprende casi en este fluido discurso, donde, de todos modos, predomina lo evanescente, la concentración de dardos contra el dictador Salazar, mediante una dialéctica ya conocida, la condena a la muerte prolongada, minuciosa de sufrimientos, ya utilizado en España en el corazón.

Particular interés tiene el apartado final de este libro, "Escritores", que puede considerarse un apéndice muy particular. Se trata de un repaso a la significación de los grandes
4

Ob. cit., p. 87

5

El cálculo está hecho, evidentemente, en el momento en que se escribe el poema.
Neruda entre dos siglos LUIS SAINZ DE MEDRANO 

do, Barcelona, Seix Barral, 1978 , p. 254

7

La Santa Biblia, Madrid, Edicio nes Paulinas, pp. 1441 y 14.42
Neruda entre dos siglos LUIS SAINZ DE MEDRANO autores del 'boom', en un momento en que este fenómeno se hallaba en su auge. Cortázar queda sentenciado con cierta ambigüedad: lenguaje difícil, pescador de escalofríos. De Vargas Llosa se resalta, en contraste con los versos salobres de su compatriota Vallejo, algo que entendemos como acusación de incongruencia: llora con los cuentos de amor y sonríe ante el dolor de su patria. Neruda se declara, tras comentar esto, como «cronista irritado», fiel a su misión de hacer las cuentas del siglo «verde», «nocturno» y «sangriento». Pero es, sobre todo, épica su indignación contra los «sexuales escritores» - probablemente se refiere ante todo a Lezama-, indiferentes a la grandeza revolucionaria del rugido de Fidel (y aquí hay que añdir 'sic'). Rulfo, Carlos Fuentes, Otero Silva, Revueltas y Siqueiros tampoco salen indemnes de este examen: «en qué quedamos; por favor?» le interroga en ímplícita acusación de no haberse abierto decididamente a las cuestiones sociales. Y, enseguida, comparecen Sábato, Onetti y Roa Bastos, que tampoco se libran de la reprimenda. Transgresores y descubridores son acusados, con un criterio de un simplismo radical, de traicionar los deberes de «llenar las panaderías/ destinadas a la pobreza» y haber optado por «el ponosófico monólogo» ("Escritores, X”).

Sólo García Márquez, merecedor de un especial fragmento, aparece libre de acusaciones, plenamente glorificado. Pero a continuación sucede algo inesperado, aunque no muy raro en el Neruda que siempre jugó a declarar sus contradicciones o paradojas: la valoración positiva va a alcanzar a todos estos escritores, en cuanto divulgadores en Europa de la realidad de los que el poeta denomina con el paronomásico y detonante gentilicio «subamericanos» ("Escritores", de nuevo; $\mathrm{X}$ ). Hay en estas voces - $\mathrm{y}$ esto nos retrotrae a "Alturas de Machu Picchu», traspasada a otros la misión allí asumida- reivindicaciones y ecos de quienes las perdieron: las viejas razas derrotadas. No está de más recordar que Neruda en el libro póstumo Para nacer be nacido (1978), recopilación de textos olvidados o inéditos, se decanta decididamente a favor de varios de estos escritores (Cortázar, Vargas Llosa, Fuentes, García Márquez), que «son desde lejos, exiliados o no, más americanos que muchos de sus compatriotas que viven de este lado del mar» ${ }^{6}$.
Discurso paradójico y hasta laberíntico. El apartado XI contiene un tardío e irónico rechazo al azul modernista que el ácrata Rubén Darío habría suscrito. Después, amargo, desolado, pero infatigable, juega con la memoria en torno a los mustios días infantiles, se acusa de desorientado, anuncia su búsqueda de escondite - no por casualidad en este obsesionado escudriñador de la naturaleza- «bajo una piedra,/ disfrazado de coleóptero» ("El caballero natural”, XI).

Y, por último, nuevas diatribas, bien explícitas, contra el siglo y sus iniquidades de las que su escritura está llamada a ser testimonio: «El siglo de los desterrados,/ el libro de los desterrados,/ el siglo pardo, el libro negro,/ esto es lo que debo dejar/ escrito y abierto en el libro,/ desenterrándolo del siglo/ y desangrándolo en el libro" ("Tristísimo siglo"). este libro, así, arquetípico, parece tener resonancias del libro de los siete sellos del Apocalipsis, sustituida -fácil sustitución-. la Bestia por la Bomba, libro que, desellado progresivamente, va mostrando las tremendas formas de la cólera divina. Compárense estos versos últimos de Fin de mundo: «Rompiendo los astros recientes,/ golpeando metales furiosos,/ entre las estrellas futuras,/ endurecidos de sufrir...» con lo que sucede al abrirse el sexto y el séptimo sello del texto de San Juan: «Cuando el Cordero abrió el sexto sello, se produjo un terremoto violento, el sol se oscureció como un saco de crin, la luna se hizo toda de sangre y las estrellas del cielo se cayeron» (...), «cuando el Cordero abrió el séptimo sello (...), fue herida la tercera parte del sol, la tercera parte de la luna y la tercera parte de las estrellas»?.

Si Borges pudo escribir una biografía, la de Tadeo Isidoro Cruz, con sólo lo ocurrido en una noche al protagonista, o la Historia universal de la infamia con la agrupación de catorce relatos y un prólogo, o la de la eternidad con siete y uno, no es objetable que Neruda defina el siglo XX como absolutamente cumplido con la sinécdoque de las visiones y juicios ofrecidos en el libro que nos viene ocupando, en la certeza de que se prolongarán en el tiempo que, para los menos avisados, una inútil lógica todavía reclama: «Estos cien años los viví/ transmigrando de guerra en guerra,/ bebiendo la sangre en los libros" ("Vivir cien años", XI). Cierto que al terminar el libro aventura, con la retórica de 
quien, siguiendo una tendencia reiterada en los momentos pesimistas, se obliga a alentar alguna confianza, alude a «mi esperanza irreductible», afirma que «sobrevive el hombre infinito" y piensa en un futuro en que, en medio del caos, «algo debe germinar», de modo que, por último, "encontraremos la alegría en el planeta más amargo» ("Canto(s)" 2$4, \mathrm{XI}$ ).

Más allá de lo apuntado —un típico esfuerzo tardío-, ¿se ha ido el poeta insensiblemente deslizando hacia la preconización del advenimiento, como en San Juan, aunque 'a lo humano', de una Jerusalén celeste, con el castigo de los perversos, el establecimiento de «la nueva ternura en el mundo» ("Canto"-1, $\mathrm{XI})$, la resurrección de los puros, dentro de la dinámica del morir-renacer, tan querida a partir del Canto general 8 por quien podría decir como Juan: «Yo (...) soy el que he oído y visto estas cosas»'. Como ha subrayado Bellini, "por encima de la angustia y de toda consideración en torno a la obstinada presencia del mal, en Fin de mundo, como en todos sus libros, Neruda queda fiel a su misión, al deber de afirmar, por encima de toda desilusión y de todo fracaso, al 'hombre infinito'10.

Los que siguen son años cruciales para Neruda, quien cede en el mismo 1969, dentro de la Unidad Popular, su candidatura a la presidencia de la República a Salvador Allende. Otro sorprendente libro de 1970, La espada encendida, se nos presenta como una nueva e inesperada apuesta por la utopía, cual si se tratara de una respuesta del poeta a su propio libro anterior, a partir de otra situación aún más literalmente apocalíptica: Rhodo y Rosía, la postrera pareja expulsada, como la primera, del paraíso, acosada por el fuego que destruye la tierra y tal vez todo el universo, se refugia instintivamente en el amor para refundar la especie humana. He aquí una propuesta en la que sigue funcionando, ahora inequívocamente, el mecanismo del «morir-renacer».

Ahora bien, advirtamos algo que no debe pasar desapercibido: en esta ocasión esto sólo se ha hecho posible acudiendo al mito, a la 'deshistorización' de la realidad, en una especie de micro-Canto general 'a lo divino'. Y arriesgamos esta comparación porque las connotaciones religiosas de La espada encendida van más allá del referente bíblico y más allá de la renuncia a un Dios que todo lo provee: radican en su condición de texto inserto entre los innumerables mitos sobre el fin del mundo que se dan en los pueblos primitivos, de los que nos habla Mircea Eliade, mitos que incluyen, en algunos casos, la creencia de que posteriormente «hará su aparición una nueva humanidad, que gozará de una condición paradisíaca» ${ }^{11}$.

El libro de Neruda, la desaparición del Ser Supremo no excluye lo sagrado, que ahora radica en la nueva humanidad, cuya madre, Rosía, no en vano puede decir, superada ya la catástrofe, como en un palimpsesto que trasluce la evangélica consigna dada a Pedro: «sobre esta piedra / esperaré para encender el fuego» ("Dicen y vivirán"). En nada disminuye la singularidad de estos poemas el respaldo, que en un antiguo trabajo ya tuvimos ocasión de señalar, de "El incendio terrestre" de Marcel Schwob ${ }^{12}$.

Esta nueva propuesta del, de todos modos, incansable utópico irá seguida del exultante Las piedras del cielo (1970), canto a la preciosa duerza de esmeraldas, ágatas, topacios y otras minerales maravillas, decantados e insignes asientos de eternidad. Lo que sigue, Geografía infructuosa (1972), la rosa separada (1972) y siete libros más de poesía hasta Incitación al nixonicidio y alabanza de la revolución chilena (1973), más los póstumos (El mar y las campanas, 2000, Jardín de invierno, El corazón amarillo, Libro de las preguntas, Elegía), son, con excepción de Incitación al nixonicidio, libros de reconocimiento de una derrota, no importa cuántas veces el poeta resurja de entre sus progresivas ruinas personales y las de su proyecto de mundo.

No hay que dejar de resaltar, antes de seguir adelante, que en el de la propuesta nixonicida, el poeta, introducido de nuevo, a todo riesgo, en la historia por la violencia de los acontecimientos que destruyeron brutalmente la última de las revoluciones quiméricas del siglo XX, organiza una batalla numantina en la que, como en las viejas gestas, se sacrifica lo que más se ama en el reducto asediado. Esto equivale a decir que Neruda inmoló, al convertirlas en armas arrojadizas, su cristalería y sus porcelanas, sus más caros bienes, sus instrumentos dúctiles para la poesía: en fin, sus palabras, su verbo lírico. Lo hizo - aunque no pudo evitar que se le escaparan ráfagas de ese verbo- porque era la hora de actuar como «palanquero, rabadán,
En el Canto general, como observa Juan Villegas, "el predomio del mal no es visto como el fin del mundo — subrayamos el coincidente sintagma- o como de permanencia indefinida. Por el contrario, es concebido como un estado transiciona en el cual se vislumbra ya el advenimiento de una nueva forma de existencia» (Estructuras míticas en el 'Canto general', Barcelona, Planeta, 1976, p. 47

9

La Santa Biblia, ed. cit., p. 1452.

10

G. Bellini, "La poesía póstuma de Pablo Neruda: entre la angustia y la esperanza", en AA.W., Coloquio internacional sobre Pablo Neruda. (La obra posterior al 'Canto general'), Poitiers, 1979, Centre de Recherches Latino-Américaines, 1979 , p. 26.

11

M. Eliade, Mito y realidad, Madrid, Guadarrama, 1973, p. 71.

12

L. Sainz de Medrano, "El último Neruda", en D. A. Yates, Otros mundos, otros fuegos. fantasía y realismo mágico en Iberoamérica, Memoria del XVI Congreso del Instituto Internacional de Literatura Iberoamericana, Michigan State University, 1975, p. 192.

Neruda entre dos siglos LUIS SAINZ DE MEDRANO 
13

P. Neruda, "Explicación perentoria", en Incitación al nixonicidio y alabanza de la revolución chilena, Barcelona, Grijalbo, 1974, p. 10.

14

J. Giordano, "Neruda y el año $2000^{\prime \prime}$, en Dioses, antidioses.. Ensayos críticos sobre poesía hispanoamericana, Concepción, Lar, 1987, p. 159.

\section{5}

A. Sicard, El pensamiento poético de Pablo Neruda, Madrid, Gredos, 1981, p. 159.

16

G. Bellini, ob. cit., p. 33.

\section{7}

O. Rodríguez, La poesía póstuma de Pablo Neruda, Gaitherburg MD, Hispamérica, 1995, p. 47.

18

Lo cita Edelberto Torres en La dramática vida de Rubén Darío, Managua, Nueva Nicaragua, 1982, p. 61.

\section{9}

P. Neruda, Para nacer he nacido, Barcelona, Seix Barral, 1978, pp. 185-186.

\section{0}

A Paz pertenecen afirmaciones como éstas: "La poesía es la Memoria hecha imagen y la imagen convertida en voz. La otra voz no es la voz de ultratumba: es la del hombre que está dormido en el fondo de cada hombre. Tiene mil años y tiene nuestra edad y todavía no nace. Es nuestro abuelo, nuestro hermano y nuestro bisnieto» (...) «Espejo de la fraternidad cósmica, el poema es un modelo de lo que podría ser la sociedad humana» (La otra voz, Barcelona, Seix Barral, 1990, pp. 136 y 138).

21

P. Neruda, Confieso que he vivido, Barcelona, Seix Barral, 1974 , p. 372.

Neruda entre dos siglos LUIS SAINZ DE MEDRANO alarife, labrador, gásfiter y cachafás de regimientos, capaz de trenzarse a puñete limpio o de echar fuego hasta por las orejas» ${ }^{13}$. Y lanzó, como otro Guzmán el Bueno - discúlpeseme el énfasis-, desde la fortaleza duramente asediada, su puñal, esas palabras transmutadas dolorosamente en ripios, en vinagres, en artefactos.

$Y$ dicho esto, ya es tiempo de considerar lo que vino después como legado purificado por su muerte. Desconocemos el tiempo de redacción de este libro, 2000, uno de los póstumos como ya hemos indicado, pero es una obra que, en cualquier caso, se distingue entre las que componen el testamento nerudiano. Se trata de un poemario en el que, como su título anuncia, el poeta se introduce osadamente en ese nuevo siglo sentido como inminente, con desacato a su propia cronología real. Si Fin de mundo representaba la clausura voluntarista del XX, 2000, texto «oracular», como lo ha definido Jaime Giordano ${ }^{14}$, significa una mirada crítica al tiempo en que, digámoslo ya, la esperada Jerusalén celeste se convierte con evidencia en la persistencia del horror. No es raro que haya unanimidad en la valoración del tono de 2000. Alain Sicard ha podido juzgar este pequeño libro como «el más sombrío de los poemas nerudianos posteriores a Residencia en la tierra» ${ }^{15}$. También Bellini advierte que el juicio del poeta sobre el mundo «es más duro que en los libros anteriores» ${ }^{16}$, y Osvaldo Rodríguez apenas atenúa el juicio de Sicard al escribir que «estamos ante una de las posiciones poéticas más sombrías después de Residencia en la tierra» ${ }^{17}$.

No faltan, es bien sabido, los ejemplos de literatura de anticipación, émula del Nostradamus que vaticinó el fin del mundo para julio del año en que nos reunimos en este Coloquio. Suele evocarse en estos casos a Wells y a Orwell, pero en Hispanoamérica podríamos recordar la novela de Abel Posse La reina del Plata (1990), con su terrible visión de una Argentina dominada por las fuerzas poderosas de los que, definitivamente y para siempre, han ocupado, sin concesiones ni ambigüedades, el poder. Recordar asimismo al poeta venezolano Andrés Eloy Blanco, quien mucho antes, en 1938, escribe su «Baedeker 2000», poema en el que se sitúa en el siglo XXI desde una posición de confianza en el mundo nuevo a la que ha llegado al adquirir «la astilla de eternidad». Y, a título de curiosi- dad, en este recuerdo de experiencias anticipadoras, resulta interesante, yendo más atrás, un texto del joven Rubén Darío en el que, apoyándose sin duda en la literatura de ciencia-ficción, tan prolífica en su tiempo, predice las realidades portentosas que la técnica traerá en la vigésima centuria: navegación submarina, aviación, televisión... ${ }^{18}$.

En una ocasión no determinada cronológicamente, Neruda, bajo el título «Contestando a una encuesta», se mostró en principio poco inclinado a opinar sobre algo relacionado con el año 2000: "¿Qué sé yo del año 2000? ¿Y, sobre todo, qué sé yo de la poesía?». Pero, centrada la encuesta, en efecto, en este tema, Neruda reivindica enérgicamente la función social de la poesía: «No es probable - dice- que comenzando el año 2000, los poetas encabecen una sublevación mundial para que se reparta la poesía. La poesía se repartirá como consecuencia del progreso humano, del desarrollo y del acceso de los pueblos al libro y a la cultura»19. Y enseguida reivindica la eternidad de la poesía, de tal modo que Homero puede ser el poeta más novedoso del siglo XXI. Muy lejos se muestra Neruda aquí de cualquier pesimismo, de tal modo que, ahondando en estas ideas, encontraríamos fácilmente concordancia con las que en el mismo sentido desarrollará más tarde Octavio Paz en La otra voz respecto a la salvación de la humanidad por la poesía ${ }^{20}$. El chileno parece pletórico de una fe en el futuro que algunos, no nosotros, calificarían de panglossiana, merced a la conexión de la poesía con el progreso.

En Confieso que be vivido, Neruda, como de pasada, se refiere también al año 2000 con un gran optimismo: «Cada Navidad que pasa nos acerca al año 2000. Para esa alegría futura, para esa paz de mañana, para esa justicia universal, para esas campanas del año 2000 hemos luchado y cantado los poetas» ${ }^{21}$. Aparecen vivas, como se ve - en un nuevo gran acto voluntarista- las expectativas de la luminosa utopía que ha de cumplirse en la fecha carismática.

Habituados como estamos por Neruda a estos vaivenes de opinión, es hora de añadir, para zanjar en último término nuestra interpretación de estas contradicciones, que, en el caso de que éstas se produzcan entre un texto en prosa, siempre que, por muy hermoso que sea, no funcione como poema, y otro de fun- 
damentación lírica, optamos por dar crédito al segundo. Y esto por la sencilla razón de que el poeta — se ha dicho muchas veces- siempre sabe más, ha estado donde el periodista, el pensador, o el declarante sorprendido en su cotidianidad nunca estuvieron, ha visto lo que aquéllos no vieron y, por otra parte, hay en el poeta un impulso hacia la expresión de su verdad que no está sujeto a las presiones de lo contingente ${ }^{22}$. El problema, desde luego permanece cuando el poeta emite apreciaciones encontradas.

Esto nos introduce en 2000, donde Neruda se alinea más bien con la posición de un Orwel en su concepción de un mundo futuro —visto desde el presente- ni más ni menos deshumanizado e injusto que el del rebasado siglo XX. También hay razones para pensar en el Vallejo de «Me moriré en París con aguacero», capaz de situarse en el futuro posterior a su muerte y escuchar las voces de quienes lamentan el injusto trato que recibió. Porque aquí, como en otros libros de esta última etapa, emerge el yo sufriente del poeta, en el plano existencial, con una intensidad que no había tal vez aparecido desde el lejano tiempo de las Residencias. En 2000 el sobreviviente de los viejos tiempos pide perdón por su inoperancia (como en Aún: "pido perdón por mi mal comportamiento. No tuvo utilidad mi gestión en la tierra» (XVI)) y manifiesta su vergüenza por la muerte de la verdad. Es preciso ante todo colocarse las «máscaras victoriosas» ("Las máscaras", p. 9)23 para afrontar ese presente del futuro. Triunfa, irónicamente, la magia de la técnica. Confusas razones nos inducen a una alegría que será abolida. Sigue la tierra impertérrita sus ciclos inalterables de fecundidad, indiferente a «la muerte que vestimos los hombres, / la maldita progenie que hace la luz del mundo" ("La tierra”, p. 23). Subyace aquí también la vieja dicotomía que ya parecía vencida entre el desorden de lo humano y la armonía de la naturaleza que cumple sus funciones y sus ciclos con precisión, como se nos había dejado bien señalado en el poema II de "Alturas de Machu Picchu".

Alain Sicard ha constatado, y Selena Millares lo ha subrayado oportunamente, la presencia textual, literal en algún caso, de Quevedo en 200024. Pero Quevedo no es sólo aquí un intertexto sino también un referente que flota por todas partes y puede entrar por cualquier resquicio, sin mengua de que haya otros. Así, los viejos muertos, los de lejanas fechas del XX, los «Pedro Páramo, Pedro Semilla, Pedro Nadie», «los fallecidos antes de esta estúpida cifra/ en que ya no vivimos» reclaman su derecho a estar asociados a los inmediatos, previsibles muertos del siglo XXI, al «honor venidero» ("Los hombres", p. 28, 29), con el que parecería estar comprometida - ¿presunción sarcástica? - la nueva centuria.

Un personaje cuya condición tipológica nos es familiar comparece para definir desde su propio yo su identidad. Es quizá uno de los supervivientes de las fantasmales gentes de "La tierra se llama Juan" en el Canto general, en particular del ser de ultratumba que se llama Margarita Naranjo: «Soy - dice-Ramón González Barbagelata, de cualquier parte,/ de Cucuy, de Paraná, de Río Turbio, de Oruro,/ de Maracaibo, de Parral, de Ovalle, de/ Lancomilla». Este "pobre diablo del pobre Tercer Mundo» exige al poeta su propia voz y cancela por el momento ciertas tendencias de su evocador a los simbolismos evanescentes. «He llegado a este mentado año 2000, y ¿qué saco,/ con qué me rasco, qué tengo yo que ver/ con los tres ceros que se ostentan gloriosos/ sobre mi propio cero, sobre mi inexistencia?» ("Los hombres", pp. 33, 34). Quizá la única diferencia es que en este caso Neruda ha transfigurado en lenguaje culto -con la salvedad del coloquialismo que acabamos de advertir - el lenguaje pobre, limitado (pero fulgurante, pero dramático) de los tristes héroes del Canto general.

También Selena Millares nos ha recordado que Nicanor Parra ha utilizado este recurso de dar voz a los muertos. Cabe, naturalmente, ir mucho más atrás, porque el procedimiento, ligado a la evidencia de que la voz que viene de la muerte tiene una excepcional pureza y, por lo tanto, gran credibilidad, nos retrotraería a Luciano de Samosta, a Dante y a Quevedo, cuyos condenados podrán ser -o haber sido- malignos, pero hablan desde la verdad; a Chateaubriand, cuyas Memorias de ultratumba fueron escritas para ser difundidas sólo cuando el autor hubiera desaparecido (cosa que no se cumplió), a Nuestra ciudad de Thornton Wilder y, claro está, a la novela de Juan Rulfo, explícitamente traída a colación por Neruda en la hipóstasis de su antihéroe.
22

Cortázar, en quien nos complace apoyarnos, ha recordado estas palabras de Chesterton, en The Trees of Pride, sobre este asunto: «El poeta tiene razón. El poeta siempre tiene razón. Oh, él ha estado aqui desde el principio del mundo, y ha visto maravillas $y$ terrores que acechan en nuestro camino, escondidos detrás de un matorral ○ una piedra..." (J. Cortázar, "Para una poética", en Obra crífica/2, ed. de Jaime Alazraki, Madrid, Alfaguara, 1994, p. 277).

\section{3}

Citamos por la edición: Pablo Neruda, 2000, Nota de Margarita Aguirre, Torre Agüero, Buenos Aires, 1975.

24

S. Millares, La génesis poética de Pablo Neruda. Análisis intertextual, Madrid, Universidad Complutense, 1992.
Neruda entre dos siglos

LUIS SAINZ DE MEDRANO 
J. C. Rovira, Para leer a Pablo Neruda, Madrid, Palas Atenea, 1991, p. 187.

26

A. Sicard, ob. cit., p. 311.

27

O. Paz, ob. cit., p. 62.
Neruda entre dos siglos

LUIS SAINZ DE MEDRANO
El «tiempo inicial» está poblado de barracones y duras miserias ¿Por qué inaugurar un siglo en el que se continúan asentando la injusticia y el hambre? En lo que - a nuestro entender - llega a parecer una parodia de un cínico discurso de posmodernidad, el desalentado poeta va cediendo también la voz al individuo paradigma de la gauche divine, el que jugó a la rebelión y a la vanguardia, pero asumió confortablemente los placeres del capitalismo: «Hoy estoy a la entrada del milenio,/ anarcocapitalista furibundo,/ dispuesto a dos carrillos a morder/ la manzana del mundo». Un mundo hecho aldea global, formando cronotopo con un tiempo florido, respirado «desde el jardín bancario» ("Los otros hombres", pp. 39, 40), maquillada la poco correcta denominación de ciertas guerras; tiempo, en fin, protegido, como ya lo estuvo el año 1000 por los tres ceros como tres nadas tan engañosas como rotundas, tapia con bardas alambradas que cierran el paso a la insurrección.

El yo, «exvanguardero ya pasado de moda» ("Los otros hombres", p. 39) observa el nuevo siglo que constata el proceso de extinción de muchas de las riquezas naturales $y$ anuncia, consecuentemente en tan renovadora línea, la invención de nuevas máquinas bélicas para seguir asesinando. Como ha escrito José Carlos Rovira, «la fórmula del canto ha asumido aquí radicalmente el principio de la desesperanza, como construcción que niega las propias utopías ${ }^{25}$.

Pero alguien, una nueva innominada elocución, propone inesperadamente, de buena fe, la celebración del nuevo siglo con la resurrección de la antigua y conocida fuerza de esperanza. Y habla este optimista impenitente -cuyo resurgimiento ya no nos sorprendede un tiempo de madurez de grandes augurios $y$, como en los primeros poemas posresidenciarios, de "nuevas banderas", mientras la regeneración corporal de ciegos, mudos, mancos y cojos nos acercan, como a Vallejo -otro apocalítico, en España, aparta de mí este cáliz-, al Libro de Isaías.

Al finalizar este último poema, advertimos la identidad de esa voz. Es, otra vez, la del poeta con su contumaz, orgulloso legado, "porfiado esqueleto de palabras» ("Celebración", pp. 49 y 50), con todo el patetismo de los estertores del amor en los tiempos del cólera.
Pero está claro que Neruda, a pesar de sus crisis y de la permanencia soterrada de su impacto, con desfallecimientos muy notorios, no dio nunca, como afirma Alain Sicard refrendando a Hernán Loyola, la imagen de un lírico «infiel a sus deberes», de «un poeta retirado al Aventino»26. En lo político, el drama de esa fractura se traslucirá en una actitud rencorosa contra el depredador de un ideal sagrado y su afirmación en la potencia de ese ideal. La exaltación de Lenin -el intocabletal como la encontramos en nueve poemas de Navegaciones y regresos, será uno de los refugios de esa afirmación. Y la Unión Soviética seguirá siendo para Neruda un referente especial, pero, sin duda, un referente más envuelto en lo sentimental que en lo ideológico. No es extraño que uno de sus últimos libros, Elegía, pueda ser leído como lo que el título declara, una melancólica añoranza de los viejos buenos tiempos, asociados a los entrañables amigos de cuando aquel país mantenía firme su capacidad de ser reducto de una gran esperanza: Luis La Casa, el arquitecto de la madrileña Ciudad Universitaria; Alberto Sánchez, el escultor toledano; Nazim Hikmet, Savic, Ilya Grigoriovich, Ehrenburg, Maiakovski, Evtuchenko, Lily Brik, Akmadulina... $Y$ tras estos nombres, un amado espacio, Moscú; la madre Rusia. Todo visto con un fervor ya más nostálgico que proyectado hacia el futuro. En definitiva, se ha producido en Neruda lo que Octavio Paz detecta como algo que caracteriza a la poesía desde el Romanticismo hasta nuestros días, en cuanto la historia de esa poesía no ha sido sino la de sus relaciones con el mito, tras haber roto el vínculo con él en la Edad Moderna para reasumirlo en la idea de la Revolución, relación turbulenta que produce numerosas oleadas de contradicciones, en cuanto «en todos los movimientos revolucionarios el tiempo sagrado del mito se transforma inexorablemente en el tiempo profano de la historia» ${ }^{27}$.

Cuando Neruda escribe su poema "Final", que aparecerá en El mar y las campanas, ya apenas le quedan las manos acogedoras de Matilde. En ese breve tiempo de figuras silenciosas en los hospitales, adormecido, casi irreal, el poeta pudo sentir que no había ya para él posibilidad de acercarse más al 2000. Tuvo que volver a emitir aquel lejano verso de la "Canción desesperada": «Es la hora de partir, oh abandonado». Y partió. 
Sería, por lo demás, injusto vincular el desaliento de Neruda, como causa exclusiva, a cuestiones íntimas y políticas. No está solo el chileno en esa actitud ante el balance del siglo $\mathrm{XX}$ y las perspectivas del inmediato. Aquí se impone una vez más una referencia a Octavio Paz, quien mantuvo con él grandes divergencias y desencuentros -aunque no dejó de considerarle su «enemigo más querido» ${ }^{28}$ A Paz pertenecen estas palabras que encierran un juicio no menos duro que el de Neruda en torno al asunto: «El temple de este siglo hace pensar a veces en los terrores del Año Mil o en la sombría visión de los aztecas que convivían con la amenaza del cíclico fin del cosmos. La modernidad nació con la afirmación del futuro como tierra prometida y hoy asistimos al ocaso de esta idea (...) Son tantas las formas en que se manifiesta el descrédito del futuro que cualquier enumeración resulta incompleta ${ }^{29}$.

$\mathrm{Si}$, para concluir, el dudoso privilegio de la extrema senectud le hubiera permitido a Neruda llegar físicamente al año 2000 en buen uso de sus facultades, habría podido percibir cómo se repetía en parte el proceso de fines del siglo XIX y principios del XX: otra vez en marcha el positivimo, pero ahora sin la contrapartida de simbolistas, krausistas, arielistas, incluso sin desconcertantes Zaratrustas, $\sin$ Daríos, sin Unamunos, sin la esperanza del élan de Bergson. Habría podido conocer ciertos versos de Mario Benedetti leídos en esta Universidad de Alicante en mayo del 97 y que podría haber firmado el propio chileno: « A dónde irán los niños y los perros/ cuando el siglo vecino nos dé alcance?/ ¿niños acribillados como perros?/ ¿perros abandonados como niños?) (...) Este fin de centuria es el desquite/ de los rufianes y camanduleros/ de los callados cuando el hambre aúlla/ de los ausentes cuando pasan lista/ de los penosos vencedores/y los tributos del olvido/ de los abismos cada vez más hondos».

$Y$ creemos que hubiera retrocedido espantado al ver deshilachada la 'revolución idolatrada' y triunfalmente instalada su alternativa: «la definitiva/ mentira patriarcal» ${ }^{30}$.
O. Paz, "Pablo Neruda (19041973)", en Vuelta, no 202, México, septiembre 1993, p. 8.

\section{9}

O. Paz, La otra voz, ed. cit., p. 50. El texto pertenece al capítulo "Ruptura y convergencia» fechado en 1986).

30

M. Benedetti, poema "Zapping de siglos", en Discurso de investidura. En C. Alemany, Remedios Mataix, J. C. Rovira (eds.), Mario Benedetti: inventario cómplice, Universidad de Alicante, 1998, p. 613. 